М.Ю. Лосєв

Харківський національний економічний університет ім. С. Кузнеия, Харків

\title{
ОЦІНКА ЦІННОСТІ ТА СТУПЕНЮ СТАРІННЯ ІНФОРМАЦІЇ ПРИ ЦЕНТРАЛІЗОВАНОМУ СПОСОБ УПРАВЛІННЯ МЕРЕЖЕЮ
}

В роботі розглядаються можливості підвищення ефективності управління комп'ютерною мережею иляхом моделювання процесу інформаційного забезпечення з урахуванням цінності та старіння інформації, щзо передається иееттром управління елементам мережі. Запропонована методика оцінки цінності інформації управління, яка доставляється до иентрів комутації, при иььому враховується інтенсивність завантаження цеентрів комутащії, їх відносну відстань від ичентру управління, час затримки доставки та обробки даних в мережі.

Ключові слова: комп'ютерна мережа, ресурси мережі, інформаційне забезпечення, керуючий центр, изентр комутації, час збору інформації, цүінність інформації.

\section{Вступ}

Постановка проблеми. Інформаційні технології перетворилися в один з найбільш значущих чинників, що сприяють розвитку сучасного суспільства. Незважаючи на істотні досягнення в області мережевих технологій, моделі і методи управління мережевими ресурсами $є$ найвужчим місцем при аналізі процесів взаємодії елементів розподілених систем. Низька ефективність застосовуваних методів збору інформації, прийняття рішення і контролю виконання цього рішення знижує якість обслуговування користувачів. Тому для виконання вимог щодо якості обслуговування в процесі проектування розробники змушені передбачати певну надмірність виконання будь-яких операцій при управлінні мережею. Це призводить до збільшення вартості як самої мережі, так і послуг, що надаються. Усунути цей недолік можна шляхом підвищення ефективності виконання технології управління мережею. Для функціонування системи управління необхідна інформація про стан елементів мережі. Ця інформація надходить 3 тієї ж мережі, може виникнути ситуація, коли вона буде неповною.

Не повна визначеність стану елементів мережі суттєво ускладнює здійснення правильного вибору варіанту рішення по управлінню мережевими ресурсами. Складність завдання розподілу ресурсів полягає в тому, що використання одних ресурсів може суттєво вплинути на ефективність використання інших. Отже, виникає необхідність розробки методів прийняття рішення при управлінні мережею в умовах інформаційної невизначеності.

Аналіз останніх досліджень і публікацій. Ефективність мережі визначається не тільки кількістю переданих повідомлень, а й їх важністю або цінністю. Важливість керуючої інформацією для елементів мережі важко переоцінити. Однак ці дані теж можуть мати різну “вагу” і істотно, а іноді і фатально, вплинути на процес функціонування мережі. Тому актуальним завданням $є$ розробка методики прийняття рішення при управлінні мережею з урахуванням цінності інформації, що передається. В [14] описані питання реалізації заданої якості обслуговування в мережах, однак в них не враховується той факт, що інформація має свою цінність, причому зі збільшенням часу затримки в передачі інформації або обслуговуванні елементів мережі цінність інформації зменшується. В [5-6] розглядаються питання невизначеності і старіння інформації на основі використання коефіцієнта довіри, який об'єднує фактори, які мають різну основу походження.

Таким чином, ефективність комп'ютерних мереж багато в чому залежить від ефективності процесу формування та доставки повної управляючої інформації центром управління до елементів мережі.

Мета статті - підвищення ефективності управління комп'ютерною мережею шляхом моделювання процесу інформаційного забезпечення з урахуванням цінності та старіння інформації, що передається центром управління елементам мережі.

\section{Виклад основного матеріалу}

Управління будь-якими процесами являє собою серію безперервних або дискретних взаємопов'язаних дій, спрямованих на досягнення поставлених цілей. Технологія централізованого управління розподіленою адаптивною комп'ютерною мережею передбачає використання одного керуючого центру комутації. Для вирішення поставлених завдань центр управління спочатку здійснює збір інформації про стан мережі і іï елементів. Після отримання інформації про стан керованих об'єктів центр управління вирішує завдання розподілу завдань між вузлами комутації. Можливий варіант централізованого управління 3 одним керуючим центром, при 
якому цей центр, отримавши інформацію, вирішує завдання розподілу мережевих ресурсів між вузлами комутації. При відсутності або спотворенні будьякої частини даних завдання управління може бути вирішене правильно або з помилкою. Результати виконання підтверджуються квитанцією центру управління і при необхідності робиться їх коригування. Таким чином, технологія централізованого управління включає наступні етапи [7]:

запит центру управління вузлів комутації на отримання інформації про стан мережі, збір інформації про стан мережі;

рішення задачі управління (обробка інформаціiі); доставка керуючої інформації в вузли комутації; рішення задачі вузлами комутації;

доставка інформації про прийняте рішення в центр управління; виконання рішення;

коригування процесу управління.

Збір інформації може здійснюватися різними способами [8]:

шляхом передачі спеціального сигналу 3 центру управління на підлеглі вузли комутації;

при кожній зміні стану вузлів комутації;

періодична передача повідомлень заздалегідь встановленим порядком.

Перший спосіб збору і обробки інформації про стан мережі включає всі перераховані вище етапи. При використанні способу управління станом мережі додається перший етап ініціалізації одним 3 центрів комутації процесу збору інформації шляхом формування запиту центру управління. При організації управління по заздалегідь встановленим порядком запити про збір даних центрам комутації відсутні, вони передають інформацію центру управління із заданою періодичністю.

За час доставки інформація старіє. В даному випадку під старінням інформації розуміється зменшення з часом іiї цінності. Весь час збору , обробки та передачі інформації управління $T_{y}$ можна визначити за формулою:

$$
T_{y}=t_{\text {зик }}+t_{\text {зиу }}+t_{\text {дічк }}+t_{\text {обр }}+t_{\text {діиу }}+t_{\text {обрик }}+t_{\text {дічк }},(1)
$$

де $t_{\text {зик }}$ - час запиту центром комутації процесу збору інформації; $t_{\text {зиу }}$ - час запиту центром управління на передачу даних центрами комутації; $t_{\text {діцк }}$

- час доставки інформації 3 центрів комутації

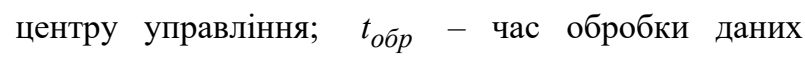

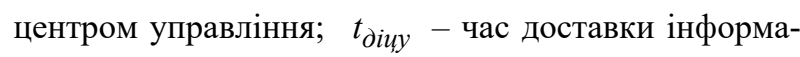
ції з центру управління центрам комутації; $t_{\text {обрик }}-$ час обробки даних центрами комутації.

Правильність рішення задач в центрі управління та на вузлах комутації залежить від того, чи є на цьому центрі необхідні знання для вирішення завдань. Якщо задачі вирішені правильно і рішення передані без спотворень, то центр управління стверджує таке рішення. В іншому випадку процес управління повертається в початковий стан. Знову здійснюється збір, передача та обробка нових даних.

Топологія системи управління зазвичай представлена вектором $h$ розмірністю $N$, де $N$ - число керованих об'єктів. Елемент вектора $h i$ характеризує відстань до $i$-го об'єкта. 3 ростом відстані до об'єкта ефективність управління падає. При цьому неможливо однозначно і точно визначити як, оскільки повідомлення передаються пакетами, і для доставки можуть бути використані різні шляхи. У загальному випадку кожен центр комутації має безліч шляхів доставки даних $з$ центру управління мережею, кожен 3 яких може бути виконаний 3 певною ймовірністю $P_{j}, j=1, \ldots z$.

Процеси передачі керуючої інформації в трактах відбуваються аналогічно і виконуються паралельно. Тому для визначення часу обробки та обміну інформацією, що управляє, логічними можуть бути такі припущення [9]: час керування об'єктами повідомлення дорівнює часу управління найповільнішим 3 них у відповідній групі; якщо при виконанні окремих операцій виникають цикли 3 різним часом їх реалізації, то при розрахунку середнього часу виконання завдання необхідно враховувати найбільший середній час одного циклу при будь-якої операції; умовою успішного управління $\epsilon$ правильне рішення задачі управління всіма об'єктами.

Для подальшого аналізу відстань між об'єктами умовно розіб'ємо на три групи. До першої групи належать об'єкти локального управління (тобто управління сусідніми об'єктами). До другої групи належать об'єкти, що знаходяться в сусідніх сегментах (на відстані 2-3 транзитних вузлів). До третьої групи належать об'єкти, що знаходяться на відстані, більшій 3 транзитних вузлів. Імовірність розподілу керованих об'єктів по групах представимо вектором $\left|P_{1} P_{2} P_{3}\right|$, де номерами позначені ймовірності віднесення об'єкта відповідно до 1, 2 або 3 групи.

Розглянемо такі варіанти розподілу відстані між керуючим і керованими об'єктами:

переважне управління локальними об'єктами $\left(P_{1}>P_{2}=P_{3}\right)$;

рівномірний розподіл $\left(P_{1}=P_{2}=P_{3}\right)$;

переважне управління об'єктами на далекій відстані $\left(P_{1}=P_{2}<P_{3}\right)$.

Тоді середній час доставки інформації $t_{\text {діиу }}$ будь-якому центру комутації з $i$-ї групи $(\mathrm{i}=1,2,3)$ можна визначити відповідно до виразу:

$$
t_{\text {ддіuy }}=P_{1} \cdot t_{1 \max }+P_{2} \cdot t_{2 \max }+P_{3} \cdot t_{3 \max },
$$

де $t_{\text {imax }}$ - максимальний час доставки інформації 3 центру управління до центру комутації $i$-ї групи. 
Визначимо можливості обліку старіння інформації. Нехай існує випадковий процес, що описує функціонування керованого об'єкта, вимірюється в момент часу $t_{0}$. Момент вимірювання від моменту використання відокремлює затримка $\Delta t$, пов'язана 3 доставкою та обробкою цього значення. За цей час вимірюваний процес прийме інше значення. Наскільки придатним для системи прийняття рішення $\epsilon$ отримане значення $x\left(t_{0}\right)$ залежить як від властивостей вимірюваного процесу, так і від апріорних знань і здібностей спостерігача.

Інтуїтивно зрозуміло, що близькі за часом значення можна передбачити з більшою точністю, ніж віддалені, і що через це зі збільшенням часу прогнозу середній квадрат помилки зростатиме. Таким чином, ймовірність старіння інформації, а отже, і ймовірність $P_{1 i}(t) \epsilon$ функцією часу, і ії вигляд залежить від характеристик керованого процесу, від властивостей алгоритму прогнозування і від закону зміни функції $I_{\text {дост }}(t)$.

Можна вказати і деякі загальні вимоги, якими повинна задовольняти функція $I_{0 i}$, а саме [10]:

1) $\Delta T_{i}=I_{\max } n p u 0<t<t_{k}$, де $t_{k}$ - допустимий час, протягом якого цінність інформації не зменшується. Так, наприклад, при передачі радіолокаційної інформації $t_{k}$ визначається періодом огляду радіолокаційної станції;

2) $I_{0 i}(t)=0$ при $t>\Delta T_{i}$, де $\Delta T_{i}$ - допустимий інтервал, по закінченню якого інформація вважається повністю застарілою;

3) при $t_{k}<t<\Delta T_{i}$ цінність інформації $\Delta T_{i}$ повинна зменшуватися від $I_{0 i}(t)$ до 0,3 деяким наближенням ця функція може бути лінійною. Зазначеним вимогам задовольняє наступна функція:

$$
I_{\text {дocm }}(t)=\left\{\begin{array}{ccc}
I_{\max } & n p u & 0 \leq t \leq t_{k_{i}} \\
I_{\max } \cdot\left(1-\frac{t-t_{k i}}{\Delta T_{i}-t_{k i}}\right) & n p u & t_{k_{i}} \leq t \leq \Delta T_{i} \\
0 & n p u & t>\Delta T_{i}
\end{array}\right.
$$

В даній формулі значення $t$ визначається часом доставки повідомлень в мережах $\left(T_{\partial о c m}\right)$. При використанні цього виразу досить задати лише один показник $t_{k}$ i співвідношення $t_{k} / \Delta T$. При $t_{k} / \Delta T=1$ цінність інформації в момент часу $t_{k}$ стрибкоподібно змінюе своє значення $3 \quad 1$ на 0 . Якщо $0<t_{k} / \Delta T<1$, тоді цінність інформації з моменту часу монотонно (лінійно) убуває від 1 до 0 до моменту часу $\Delta T_{i}$.

Поняття старіння інформації нерозривно пов'язане $з$ поняттям іiі цінності. Тому старіння інформації призводить до зміни від часу функції (3) і ймовірності своєчасного вирішення поставленого завдан- ня. Можна вказати деякі загальні вимоги, яким повинна задовольняти функція, аналогічні вимогам при обліку старіння інформації [11].

Функцію (3) можна розглядати с точки зору приналежності отриманої інформації іiі істинному максимальному значенню, яке змінюється з часом. Сформулюємо вимоги, якими повинна задовольняти така функція $\mu_{1}(t)$ :

$$
\begin{aligned}
& \text { 1) } \mu_{1}(t)=1 \text { при } 0<t<t_{k} ; \\
& \text { 2) } \mu_{1}(t)=0 \text { при } t>\Delta T_{i} \text {; } \\
& \text { 3) } п р и \quad t_{k}<t<\Delta T_{i} \text { функція } \mu_{1}(t) \text { повинна }
\end{aligned}
$$
зменшуватися відповідно від 1 до 0 .

Якщо є нечітка множина, яка характеризує наявність повної чи неповної інформації, то повинна бути і нечітка множина втрати інформації:

$$
\mu_{2}(t)=1-\mu_{1}(t)
$$

Вираз (3) буде перетворено в наступну функцію приналежності значенню параметра $I_{\max }$ :

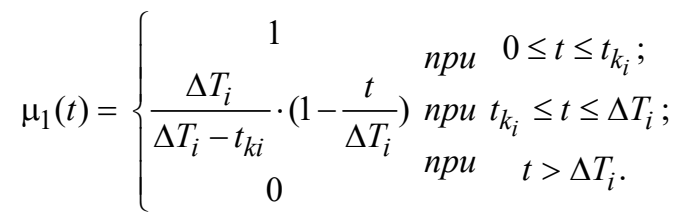

Значення функції $r_{1}=\mu_{1}(t)$ в момент часу доставки керуючої інформації до адресата може характеризувати відносний рівень цінності інформації в результаті їі старіння. Значення функції $r_{2}=\mu_{2}(t)$ характеризує відносний рівень втраченої цінності інформації або іiі ступінь старіння. Тоді, реальна цінність одержуваної інформації $i$-м об'єктом (центром комутації) в заданий момент часу можна оцінити за формулою:

$$
I_{p i}=r_{1 i} \cdot I_{\max } \cdot
$$

Визначимо, яку цінність може представляти інформація для ділянки мережі і їі об'єктів, що знаходяться під управлінням єдиного центру. Для кожного об'єкта мережі керуюча інформація “безцінна”. Однак, для всієї мережі в цілому, дані для кожного окремого об'єкта мають різну вагу. Якщо допустити, що всі повідомлення, інформаційні потоки і абоненти рівноцінні, то керуюча інформація буде найціннішою для найбільш завантажених об'єктів, що працюють 3 найбільшою відносною інтенсивністю. Припустимо, що на $i$-й центр комутації надходить потік інформації з інтенсивністю $\lambda_{\text {вxi }}$ :

$$
\lambda_{\text {Bxi }}=\sum_{j=1}^{M} \gamma_{B x j},
$$

де $\gamma_{6 x j}-$ інтенсивність потоку від $j$-го джерела; $M-$ кількість джерел інформації.

Вага $i$-го центру комутації $\Delta W_{i} \epsilon$ відносною частиною потоку до сумарного потоку в мережі 


$$
\Delta W_{i}=f\left(\frac{\lambda_{B x i}}{\lambda_{B x}}\right)=f\left(\lambda_{B x i} / \sum_{i=1}^{N} \lambda_{B x i}\right) .
$$

При вирішенні конкретних завдань кожен потік має певну корисність. Тому при управлінні чисельне значення $\Delta W_{i}$ має враховувати не тільки $\lambda_{\text {вxi }}$, а й цінність цього потоку. Це питання детально розглянуто в [12], в даному контексті будемо вважати, що всі потоки мають однакову корисність. Тоді, відповідно (5), отримаємо

$$
I_{p i}=r_{1 i} \cdot \Delta W_{i} .
$$

Цінність отриманої інформації $C_{i н \phi}$ центрами комутації від центру управління з урахуванням іiі старіння даних оцінюється показником за формулою:

$$
C_{i H \phi}=\sum_{i=1}^{N} r_{1 i} \cdot \Delta W_{i}
$$

Методика оцінки цінності інформації, що управляє, одержуваної центрами комутації, складається 3 наступних етапів:

визначення відносної інтенсивності завантаження кожного центру комутації;

визначення функцій приналежності $\mu_{1}(t)$ i $\mu_{2}(t)$ відповідно до технічних вимог доставки повідомлень в мережі; визначення середнього часу доставки повідомлень до кожного центру комутації;

обчислення показника оцінки цінності одержуваної інформації.

\section{Висновки}

Технологія централізованого способу управління мережею передбачає такі етапи, як збір інформації про стан мережі і окремих іiі елементів, рішення задачі розподілу завдань між вузлами комутації, доведення до всіх керованих об'єктів результатів цього рішення, виконання поставлених завдань центрами комутації, контроль виконання рішення i при необхідності коригування процесу управління.

3 метою виявлення шляхів підвищення ефективності систем мережевого управління запропонована методика оцінки цінності інформації управління, яка доставляється до центрів комутації від центру керування мережею. При цьому показник оцінки цінності інформації враховує інтенсивність завантаження центрів комутації, їх відносну відстань від центру управління, час затримки доставки та обробки даних в мережі. Показник може характеризувати відносний рівень зниження цінності інформації в результаті їі старіння. Це дає можливість розробляти обгрунтовані вимоги до характеристик комп'ютерних мереж.

\section{Список літератури}

1. Лосев Ю.И. Методы и модели обмена информацией в распределенных адаптивных вычислительных сетях с временной параметризацией параллельных процессов: монография / Ю.И. Лосев, С.И. Шматков, К.М. Руккас. - Х.: ХНУ им. В.Н. Каразина, 2011. - 204 с.

2. A Survey on Communication Protocols for Wireless Sensor Networks / I. Jang, D. Pyeon, S. Kim, H. Yoon // Journal of Computing Science and Engineering. - 2013. - Vol. 7. - No. 4. - P. 1640-1650. https://oi.org/10.1109/ TWC.2013.022013.120477.

3. Лосєв Ю.І. Моделювання процесу збору інформації в розподілених ієрархічних мережах / Ю.І. Лосєв, М.Ю. Лосєв // Збірник наукових праць Харківського національного університету Повітряних Сил. - 2020. - Вип. 1(160). - С. 59-66. https://doi.org/10.30748/zhups.2020.160.07.

4. Minukhin S.V. Analysis of ways for exchanging data in networks with package commutation / S.V. Minukhin, D.E. Sitnikov, M.U. Losev // Radio Electronics Computer Science Control. - 2018. - No. 4.- P. 196-204. https://doi.org/ 10.15588/1607-3274-2018-4-19/zntu.2018.04.10.

5. Руккас К.М. Методика анализа эффективности системы управления компьютерными сетями / К.М. Руккас, Ю.И. Лосев // Вісник Харківського національного університету. - 2010. - Вип. 890. - С. 154-165. vhnu.2010.890.15.

6. Модель технологии информационного обеспечения задач управления / С.И. Шматков, Ю.И. Лосев, К.М. Руккас, М. Саламе, А. Арабиат // Научные ведомости БГУ. - 2013. - Вып. 28/1. - С. 34-42. nbgu.2013.28.09.

7. Mechanism of Multiprotocol Label Switching for Forwarding Packets \& Performance in Virtual Private Network / K.N. Qureshi, A.H. Abdullah, A.N. Hassan, D.K. Sheet // Anwar Middle-East Journal of Scientific Research. - 2014. - Vol. 20. - No. 12. - P. 2117-2127. amejsr.2014.20.12.

8. Minimum Information Exchange in Distributed Systems [Electronic resource] / F. Solowjow, A. Mehrjou, B. Schölkopf, S. Trimpe // 57th IEEE Conference on Decision and Control (CDC). - 2018. - Access mode: https://arxiv.org/abs/1805.09714.

9. Rosas E. Survey on Simulation for Mobile Ad-Hoc Communication for Disaster Scenarios / E. Rosas, N. Hidalgo, V. Gil-Costa // J. Comput. Sci. Technol. - 2016. - No. 31. - P. 326-349. https://doi.org/10.1007/s11390-016-1630-X.

10. Ahlawat M. Different Communication Protocols for Wireless Sensor Networks: A Review / M. Ahlawat, A.Mitta // International Journal of Advanced Research in Computer and Communication Engineering. - 2015. - Vol. 4. - Issue 3. P. 213-216. https://doi.org/10.17148/ijarcce.2018.4351.

11. Інформаційні технології: Проблеми та перспективи: монографія / В.С. Пономаренко, С.П. Євсеєв, О.Г. Руденко, О.О. Смірнов. - Х.: Вид. Рожко С.Г., 2017. - С. 120-136.

12. Інформаційні технології: сучасний стан та перспективи: монографія / В.С. Пономаренко, I.О. Ушакова, М.М. Корабльов, М.Ю. Лосєв. - Х.: Вид. ТОВ “ДІСА ПЛЮС”, 2020. - 412 с. 


\section{Відомості про автора:}

Лосєв Михайло Юрійович

кандидат технічних наук

доцент Харківського національного

економічного університету ім. С. Кузнеця,

Харків, Україна

https://orcid.org/0000-0002-2393-3490
Information about the author:

Mihailo Losev

Candidate of Technical Sciences

Senior Lecturer of Simon Kuznets Kharkiv

National University of Economics,

Kharkiv, Ukraine

https://orcid.org/0000-0002-2393-3490

\title{
ОЦЕНКА ЦЕННОСТИ И СТЕПЕНИ СТАРЕНИЯ ИНФОРМАЦИИ ПРИ ЦЕНРАЛИЗОВАННОМ СПОСОБЕ УПРАВЛЕНИЯ СЕТЬЮ
}

\author{
М.Ю. Лосев
}

В работе рассматриваются возможности повышения эффективности управления компьютерной сетью путем моделирования процесса информационного обеспечения с учетом иенности и старения информации, которая передается центром управления элементам сети. Предложена методика оценки ценности информации управления, которая доставляется центрам коммутации, при этом учитывается интенсивность загрузки иееттров коммутации, их относительное расстояние от центра управления, время задержки при доставке и обработке данных в сети.

Ключевые слова: компьютерная сеть, ресурсы сети, информачионное обеспечение, управляющий центр, центр коммутации, время сбора информации, иенность информации, старение информации.

\section{OVALUE AND AGING EVALUATION OF INFORMATION WITH A CENTRALIZED METHOD OF NETWORK MANAGEMENT}

\section{Losev}

Information about the state of network elements is required for the functioning of the control system. Since this information comes from the same network, a situation may arise where it is incomplete or inaccurate. Therefore, there is a need to develop methods of decision-making in network management in conditions of information uncertainty.

The effectiveness of a network is determined not only by the number of messages transmitted, but also by their importance or value. The importance of control information for network elements cannot be overemphasized. This data can significantly, and sometimes fatally, affect the process of network functioning. Therefore, an urgent task is the development of decision-making methods for network management, considering the value of the transmitted information.

The paper discusses the possibilities of improving the efficiency of computer network management by modeling the information support process, taking into account the value and aging of information that is transmitted by the control center to the network elements. For every object in the network, control information is "invaluable". However, for the entire network, the data for each individual object has a different weight. The paper formulates what value information can be for a section of the network and its objects under the control of a single center. In this case, the control information will be the most valuable for the most loaded objects, working with the greatest relative intensity.

Aging of information is considered from the point of view of the received information belonging to its true or maximum value, which changes over time. The value of such a membership function at the time of delivery of control information to the addressee can characterize the relative level of information value as a result of its aging, as well as the relative level of the lost information value or the degree of its aging. The paper proposes a method for assessing the value of control information that is delivered to the switching centers. This takes into account the load intensity of the switching centers, their relative distance from the control center, the delay time in the delivery and processing of data in the network.

Keywords: computer network, network resources, information support, control center, switching center, information collection time, information value. 